\title{
عروض مختصرة
}

فتحي ملكاوي

1. Hernands, De sots, the Mystery of capital: why capitalism

Triumphs in the west and Fails Everywhere Else? London: Bantam press, 2000,244 p.

الكتاب بالإنكليزية وعنوانه سر رأس المال: لماذا انتصرت الرأسمالية في الغرب وفشلت في كل مكان آخر.

ومؤلفه مؤسس ورئيس معهد الحرية والديمقراطية في جمهورية بيرو في أمريكا اللاتينية. وتعتقد مجلة الإيكونومست أن هذا المعهد هو ثاني أهم بيوت الخبرة في العالم، واختارت مجلة التايم المؤلف ضمن أهم خمسة مفكرين في أمريكا اللاتينية في القرن العشرين. والكتاب خلاصة عمل فريق من الباحثين عملوا لمدة خمس سنوات في بلدان العالم الثالث والبلدان التي كانت تحت السيطرة الشيوعية، لجمع البيانات المتعلقة بالأوضاع الاقتصادية. ويعرض الكتاب حقائق مهمة تشير على أن البلدان الفقيرة قد جمعت من الثروة ما يكفي لتحقيق نفس النجاح الاقتصادي في البلدان الرأسمالية. وأن تلك الثروة هي أضعاف المساعدات والاستثمارات الأجنبية التي تلقتها تلك البلدان منذ عام 1945م، لكن سبب الفشل يتركز في أن هذه البلدان لا تعرف العملية التي تحول هذه الثروة إلى رأسمال سائل قادر على توليد مزيد من الثروة، كما يكمن وراء آلاف الوثائق الخاصة بقوانين الملكية. والعملية المشار إليها هي راس المال.

2-البدوي، يوسف أحمد محمد، مقاصد الثريعة عند ابن تيمية. عمان: دار النفائس، 2000، 608 ص.

أصل هذا الكتاب أطروحة لنيل درجة الدكتوراه في الفقه وأصوله من الجامعة الأردنية /كلية الشريعة، عام

1999م، وتبلور هذه الرسالة موضوع مقاصد الشريعة عند ابن تيمية. استهل المؤلف هذه الرسالة بتعريف بابن تيمية وبعلم المقاصد، ثم عرض أبرز موضوعات المقاصد عند ابن تيمية، ووضح أهم قضايا المقاصد عنده ثم جلى الباحث بعد ذلك علاقة المقاصد بالأدلة المتفق عليها وهي: الكتاب والسنة والإجماع، والأدلة المختلفة فيها، وهي: القياس والاستصحاب والمصالح المرسلة وسد الذرائع وإبطال الحيل وقول الصحابي والاستحسان والعرف وشرع من قبلنا ثم 
علاقة المقاصد بالسياسة الشرعية، وبعدها ضرب المؤلف الأمثلة من أقوال ابن تيمية على حفظ الضروريات والحاجيات والتحسينات. وأبرز الكاتب أخيراً دور ابن تيمية في علم المقاصد واستفادة الشاطبي منه، واعتدال ابن تيمية في المقاصد، وبناء الاستدلال على مقاصد الشريعة، وربطه بين المقاصد وأصول الفقه ووفرة تطبيقاته المقاصدية، و تأصيله القواعد المقاصدية، ومراعاته مقاصد المكلفين، وجاءت بعد ذلك خاتمة اشتملت على أهم نتائج هذه

3- الميلاد، زكي. محنة المثقف الديني مع العصر. بيروت: دار الجديدة، 2000 م، 144ص.

يشير الكاتب إلى ظاهرة مقلقة وهي أن كثيراً من أذكياء الأمة يكتسبون تكوينهم الفكري والثقافي والعلمي بعيداً عن الدين، وينتهي بكم الأمر إلى الاغتراب عن الدين وعن البيئات الاجتماعية للأمة. وتغيب مع هذه الظاهرة عن ساحة الأمة شخصيات جمعت بين الثقافة الواسعة وبين التجديد الديني مثل إقبال ومالك بن نبي ومحمد باقر الصدر. ويهاول الكاتب أن يفسر هذه الظاهرة بالإشارة إلى طبيعة الفهم الديني وعلاقته بالثقافة والفكر والعلم، وموقف الفكر العربي والنزعة النقدية في تكوين المثقف المعاصر. ويؤكد على الحاجة إلى انبعاث المثقف الديني الذي يجمع بين خصائص الثقافة المعاصرة ومصادرها والفهم الديني السليم.

4- الشرقاوي، المالقي عائشة. البنوك الإسلامية: التجربة بين الفقه والقانون والتطبيق. الدار البيضاء: المركز

$$
\text { الثقافي العربي، 2000م،704ص. }
$$

أصل الكتاب أطروحة دكتوراه دولة في الحقوق قدمتها الباحثة في جامعة سيدي محمد بن عبد الله بالرباط /المغرب. ويتضمن الكتاب دراسة عينة يختارة من البنوك الإسلامية التي كان لما صفة الريادة في عدد من البلدان، وتمثل أنواعاً مختلفة من البنوك من الناحية القانونية. وقد أعطى الكتاب نظرة شمولية عن جوانب متعددة من بتربة البنوك الإسلامية من الناحية القانونية والفقهية والاقتصادية، وبين جوانب الإنجاز والإيجابيات التي تحضت عنها هذه 
الجديدة. كما بين الكتاب ايضاً الإخفاقات والسلبيات التي رافقت هذه التجربة في جوانبها المختلفة. وبذلك قدمت الباحثة دراسة تتصف بالموضوعية في التناول والمكم، كما قدمت توصيات ومقترحات محددة لترشيد مسيرة البنوك الإسلامية وتطوير أعمالها.

5- Chapra, M. Umer. The future of economics: An Islamic perspective. Leicester, UK: the Islamic foundation. 2000, 446p .

الكتاب باللغة الإنكليزية وعنوانه بالعربية "مستقبل الاقتصاد: رؤية إسلامية" ومؤلفه واحد من رواد الاقتصاد الإسلامي، وله عدد من الكتب وكثير من البحوث والمقالات العلمية المنشورة. ويثير الكتاب عدداً من الأسئلة

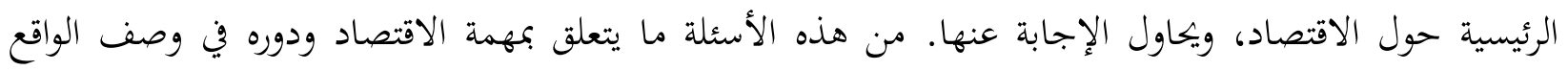
والتعامل معه مقابل تحقيق رؤية عحدة،والفرق بين الرؤية الإسلامية والرؤية الاقتصادية التقليدية، ومدى الحاجة إلى الى التعامل مع العوامل التاريخية والنفسية والأخلاقية والاجتماعية التي تعمق الفجوة بين الرؤية والواقع، والطريق إلى جسر

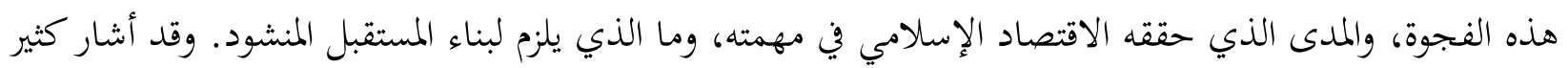
كمن راجعوا الكتاب إلى أنه لا يستغنى عنه في السعي لفهم الاقتصاد الإسلامي وتطويره.

6- Ramadan, Tariq. To be a European Muslim. Leicester, UK: the Islamic Foundation,1999,274p .

الكتاب باللغة الإنكليزية وعنوانه بالعربية "أن تكون أوروبياً مسلماً". قدم للكتاب جورغان نلسين مدير مركز دراسات الإسلام والعلاقات الإسلامية المسيحية بجامعة بيرمنغهام في المملكة المتحدة. ويعرض الكتاب لعدد من

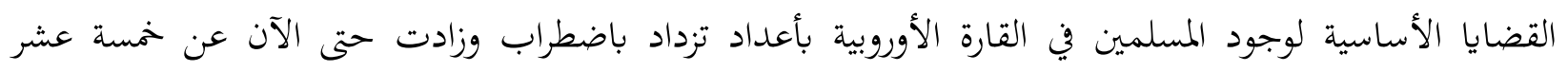

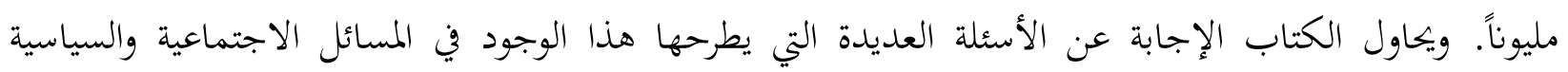

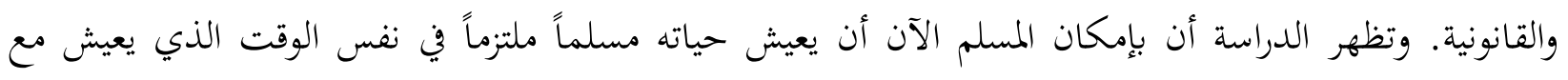


الآخرين في دول قومية متعددة الأديان. ويتعرض الكتاب في الجزء الأول إلى أساسيات العلوم الإسلامية وما يرتبط بها من أصول الفقه وخصوصياةًا المتعلقة بحياة المسلمين في أوروبا. أما الجزء الثاني من الكتاب فيتناول القضايا الحساسة التي تمس الهوية والانتماء والمواطنة والمبادئ العامة التي تحكم تعايش المسلمين مع غيرهم في الأقطار الأوروبية.

7- Abdelkader, Deina. Social Justice in Islam. Herndon, VA: International Institute of Islamic thought, 2000,216p .

الكتاب بالإنكليزية وعنوانه بالعربية: "العدالة الاجتماعية في الإسلام"، والكتاب في الأصل أطروحة دكتوراه قدمتها الباحثة في جامعة ميرلاند في الولايات المتحدة الأمريكية سنة 1995.ترى مؤلفة الكتاب أن مسائل العدل الاجتماعي مرتبطة بظاهرة البعث الإسلامي المعاصرة باعتبار أن هذه الظاهرة هي سعي الحركات الإسلامية نحو تحقيق مقاصد العدل الاجتماعي، التي فشلت الدول في المجتمعات الإسلامية في تحقيقها. وتستعمل المؤلفة مفهومي المقاصد والمصالح العامة في الشريعة وتستقصي العلاقة الجملية بين الفقه والواقع، لتؤكد أن هذين المفهومين أداتان منهجيتان في دراسة العلوم الاجتماعية والظاهرة الاجتماعية بشكل عام.

وتتضمن فصول الكتاب مراجعة لأدبيات الحركة الإسلامية المعاصرة وعلاقة هذه الحركة بالشريعة وبتوقعات

الشعوب المسلمة. كما تتضمن استعراضاً لموقع الخطاب الديني في الواقع المعاصر لكل من مصر والجزائر وتركيا.

8- Al Najjar, Abd al Majid. The viceregency of mon between Revelation and Reason: A Critique of the Dialectic of the Text, Reason, and Reality. Herndon, VA: International Institute of Islamic thought,2000,90p.

هذا الكتاب هو التربمة الإنكليزية لكتاب: "خلافة الإنسان بين الوحي والعقل: بحث في جدلية النص والعقل والواقع" للدكتور عبد المجيد النجار. 
والكتاب إسهام معاصر في الجدل الذي أثير في الفكر الإسلامي منذ وقت مبكر وما زال قائماً حول العلاقة بين الوحي والعقل. ويوضح الكتاب أن التعبير الصحيح عن المقيقة لا يمكن أن يستغني عن أي منهما وأن دورها يتآزر في تأكيد موقع الاستخلاف الإنساني في الأرض سواءً على مستوى فهم النص أو على مستوى تطبيق مبادئ الوحي في مسائل الوجود الإنساني في الأرض في حدود الزمان والمكان.

\section{9- البنّّ رجب. الإسلام والغرب. القاهرة: دار المعارف، 2000.}

مؤلف الكتاب كاتب صحفي يعمل رئيساً لتحرير مجلة أكتوبر ورئيساً لملس إدارة المعارف، وقد شارك شيخ

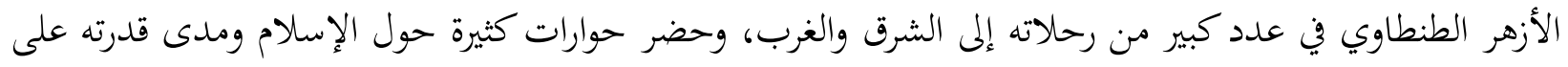

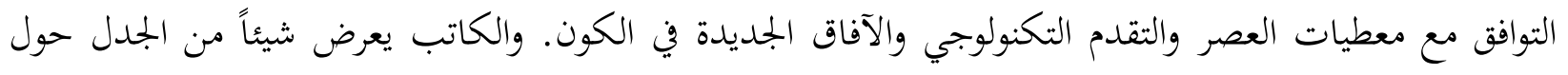

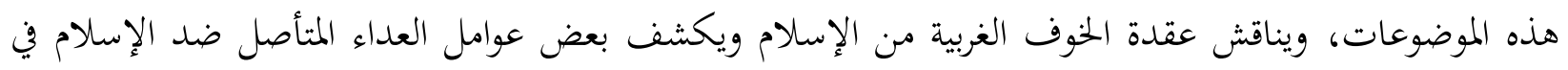
الغرب.

10- Al-Ghazali, Muhammad. The socio-political thought of Shah Wali Allah. Islamabad: The International Institute of Islamic thought, 2001, 336p.

الكتاب بالإنكليزية وعنوانه "الفكر الاجتماعي السياسي لشاه ولي الله". المؤلف أستاذ ورئيس وحدة العلوم الإسلامية والاجتماعية في الجامعة الإسلامية العالمية-باكستان. يعرض الكتاب عناصر الرؤية الكلية لمفكر إسلامي كبير من الهند عاش في مرحلة حرجة من التاريخ الإسلامي وتوفي في عام 1176هـ (1762م) ويتميز فكره بتكامل معارف العقل والوحي والتجربة، وبالجمع بين اهتمام الإنسان بقضايا الوجود والأخلاق والمقاصد الروحية في الحياة.

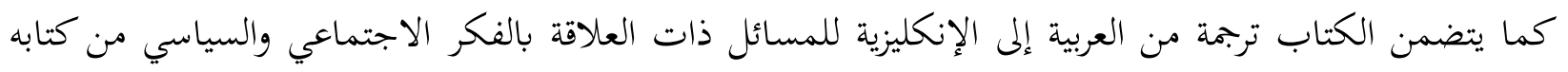
المشهور حجة الله البالغة. 
11- Armstrong, Karen. Islam: A Short History. London: Weidenfeld \& Nicolson, 2000.

الكتاب بالإنكليزية وعنوانه "الإسلام: تاريخ موجز". المؤلفة راهبة كاثوليكية تحولت إلى مدرسة جامعية لدراسة

تاريخ الأديان، وأصدرت عدداً من الكتب التي نالت شهرة واسعة، كان منها كتاب تاريخ القدس عتماز المؤلفة بلموضوعية وحصلت على جائزة المجلس الإسلامي للعلاقات العامة في كاليفورنيا عام 1999.

يااول الكتاب أن يصحح الصور النمطية الخطأ الشائعة في الخيال الشعبي الغربي الذي لا يرى ديناً في العالم

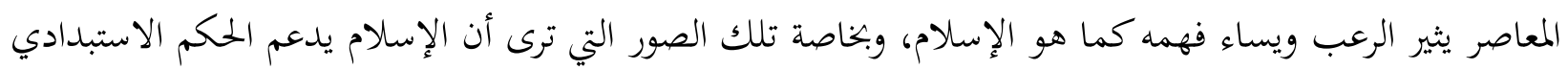
ويضطهد المرأة ويثير الحروب الأهلية ويشجع الإرهاب.

وتستعرض المؤلفة تاريخ الإسلام منذ البعثة النبوية والخلافة الراشدة والحكم الأموي والعباسي والحروب الصليبية والغزو الغربي الاستعماري، ويختم الكتاب بتقويم التحديات التي تواجه الإسلام اليوم. 